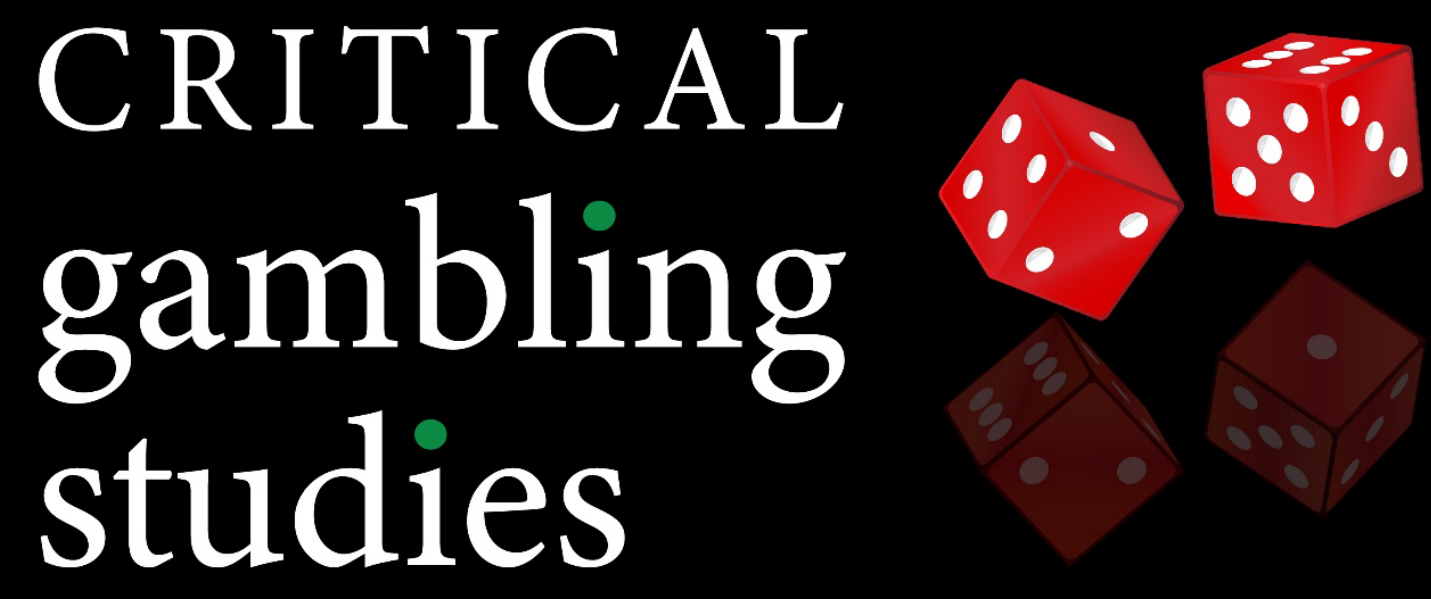

\title{
Gambling Ain't What It Used To Be: The Instrumentalization of Gambling and Late Modern Culture
}

James Cosgrave

APA Citation: Cosgrave, J. (2022). Gambling Ain't What It Used To Be: The Instrumentalization of Gambling and Late Modern Culture. Critical Gambling Studies 3 (1), 12-23.

https://doi.org/10.29173/cgs81

Article History:

Received 2020-09-10

Accepted 2021-10-06

Published 2022-03-07 


\title{
Gambling Ain't What It Used to Be: The Instrumentalization of Gambling and Late Modern Culture
}

\begin{abstract}
James Cosgrave a1
${ }^{a}$ Dept. of Sociology, Trent University Durham

Abstract: This article addresses significant cultural macro-processes shaping legalized gambling as a mass consumer market, which also serve various state and private industry ends. The processes examined here are "instrumentalization" and rationalization, explored through the seminal formulations of Max Weber and developed further in the work of Jurgen Habermas. Instrumentalization relates to Weber's concepts of rationalization and instrumental rationality, as well as to Habermas's distinction between the "system" and "lifeworld". While the phenomenon of instrumentalization is approached largely from a macroperspective, it is understood to have effects on the lifeworld, on social action, and the formation of (gambling) subjectivities. The discussion of instrumentalization and rationalization, as broad cultural processes, contributes to the genealogy of gambling in (late) modern culture. It also serves to develop a particular theoretical trajectory within critical gambling studies and indicates themes that could be opened up for further analysis.
\end{abstract}

Keywords: Gambling, instrumentalization, rationalization, Weber, Habermas

Article History: Received September 10, 2020; Accepted October 6, 2021; Published March 7, 2022

Available Open Access from https://doi.org/10.29173/cgs81

\section{Introduction}

As legal gambling has expanded rapidly in many countries, and is mass-marketed through advertising, it comes to be framed as just another type of consumption activity or form of "entertainment" pursued by individuals. However, for the sociological and cultural analysis of gambling, the social and historical transformation of gambling into a common consumption activity, and the links of gambling to various social processes and institutions that frame the discursive representation and understanding of gambling deserve scrutiny. Thus, gambling is not merely an activity that particular individuals engage in, it is an institutionalised phenomenon that links to larger social processes and interests which influence and shape action at the individual and subjective levels. The desire to gamble is shaped by, and a consequence of cultural and economic factors and socialization processes: in periods of its illegality, and where gambling venues are covert, the social actor must be socialized to want to participate in an illegal activity, and learn how to find the venues (Sutherland, 1947).
When gambling is legal, socialization takes place in part through the mass media and advertising, where "pro gambling" messages are disseminated. The "individual" proclivities and motivations (Weber, 1949; Binde, 2013) are thus linked to socialization processes rooted in a broader social milieu and institutions. Gambling desires are further stimulated by the organization of venues (e.g., casinos) and games, and the application of technological and psychological knowledges used to solicit gambling consumption (Schüll, 2012).

This discussion considers the broader social processes shaping legal gambling offerings, and the institutions that have an interest in them: namely capitalist enterprises interested in profit and states interested in generating revenues and other governmental objectives. The analysis offered here contributes to a genealogy of gambling, developing the notion of "instrumentalization" and related concepts formulated in the work of Max Weber and elaborated in the social theory of Jurgen Habermas. The discussion of instrumentalization offers an approach to the analysis of cultural processes related to the expansion of

${ }^{1}$ Corresponding author. Email: jimcosgrave@trentu.ca 
gambling, which interact with, and have consequences for, the subjectively meaningful dimension of gambling activity (Weber, 1978). Gambling instrumentalization is thus linked to the development of forms of late modern subjectivity.

The discussion also contributes to the extension of social-theoretical perspectives into the field of gambling studies. It has been noted by gambling scholars that social theory has been underutilized in the field (Cosgrave, 2006, 2020b; Egerer et al., 2020). Some recent work has sought to address this issue, with contributions engaging with, among other theorists: Slavoj Zizek (Bjerg, 2011), Michel Foucault (Nicoll, 2019), Erving Goffman (Cosgrave, 2020a), Niklas Luhmann (Egerer et al, 2020) and Emile Durkheim (Cosgrave, 2021). With the exception of Goffman (1967) these theorists did not theorize gambling. Max Weber's voluminous oeuvre reveals scant references to the topic. His work, however, remains one of the great untapped treasure troves for gambling analysis, and its applicability is potentially wide-ranging: along with the methodological emphasis on his conceptions of meaningful social action (Weber, 1978; Cosgrave, 2020a) and "cultural significance" (Weber, 1949), there is his powerful theorization of "rationalization"(1974, 1992) which has been used sparingly in gambling studies (Schüll, 2012; Levy, 2015) and is discussed here, his important analyses of social stratification and inequality (1978), his theorization of the relationship of (religious) ethics to social action (1978), and his analysis of the changing contours of characterology (such as we find in The Protestant Ethic and The Spirit of Capitalismhenceforth $P E$ ). Jurgen Habermas develops Weberian themes in his influential work on "communicative action" (Habermas, 1984, 1987). The themes of rationalization and instrumental rationality are elaborated by Habermas (1984) in connection with his theorization of societal rationality, explored through his distinction between "system" and "lifeworld", and his notion of the "colonization of the lifeworld", which are taken up here. The discussion thus extends Weberian and Habermasian social theory into gambling studies, and serves to indicate possible comparative linkages with other social theoretical perspectives. Weber's (1974, 1978) analyses of rationalization, power, and authority for example can be productively linked to the Foucauldian concepts of "governmentality" (Foucault, 2008) and "bio-power" (1998, 2008) both fruitful concepts for critical gambling studies (see Nicoll, 2019, 14-18; Wilcox, 2021). Notwithstanding the profound theoretical differences between Habermas and Foucault (Ashenden and Owen, 1999), their particular critical theoretical formulations of power and discourse could also be productively deployed in gambling studies analyses. They both offer particular ways of conceiving subject formation in late (or post) modernity.

\section{On Instrumentalization}

Instrumentalization here means the shaping, implementation, and use of gambling activities, enterprises, and venues, and the concomitant generation of gambling activity and actors' desire to gamble, for the purposes of various social, organizational, or policy ends, the most prominent being capitalistic profit and state revenues. These ends are largely taken-for-granted now that gambling has been legalized and expanded. However, instrumentalization signifies a discursive framing that depends upon, and further promotes, the rationalization and commercialization of gambling, whereby gambling is subjected to an instrumentalizing vision (instrumental rationality) which shapes the activity. Instrumentalized gambling policy is made possible by gambling legalization, and is instituted as gambling is socially legitimated and oriented to for its surplus-creating possibilities. Ongoing gambling revenue-seeking and competition further promotes instrumentalization, which both promotes, and is the product of, a rationalizing gambling culture.

Instrumentalization generates a productive orientation to the possibilities that gambling practices open up, but at the same time signifies a discursive "taming" of the activity in that it renders gambling manipulable as (instrumentalized) means. This manipulability however, must ( $p$ )reserve a space for chance - or the appearance of it - in order to procure participation. Instrumentalization addresses two interrelated dimensions: the broader cultural processes shaped by the state, governments, and private gambling industry that act within and intervene in the cultural realm, and the sphere of social action (Weber, 1978), which is itself shaped by cultural processes, as well as through the particular interactions actors have with gambling venues and the various gambling technologies. Instrumentalization produces reciprocal reflexive effects in each dimension.

The ongoing legalization and expansion of gambling is related to the pressures generated by the capitalistic search for (new) sources of profit, and the state and governmental search for (new) sources of revenue (as well as other economic objectives), both of which are occurring culturally in the context of transnational capitalism and the increased financialization of global markets related to neoliberal political-economic values and ideologies. The late $20^{\text {th }}$ century expansion of gambling dates back to the 1960s and 1970s, when states and governments legalized or reintroduced lotteries. The legalization and expansion of casinos and other gambling forms (such as electronic gaming machines - henceforth EGMs), beginning roughly in the late 1980s and early 1990s, occurs fully in the context of neoliberalism - understood here as the re-emergence of the economic ideology of "free marketism", the deregulation of a number of economic enterprises and sectors, and the replacement of public provisions with privatized market "solutions". An 
important dimension of gambling instrumentalization occurs through and is enabled by government policy, which in turn relates to the shaping of public discourse pertaining to state and governmental activities such as taxation, economic development and management. Instrumentalized gambling policy acts within and utilizes culture (Yúdice, 2003) and produces social effects: from the shaping of urban spaces due to casino implementation, to possible social (and personal) costs, some of which are generated from the promotion and accessibility of gambling opportunities. These effects have reflexive characteristics, which are discussed below.

\section{Rationalization, Culture, and Chance}

The concept of instrumentalization relates directly to Max Weber's (1978) concept of "instrumental rationality" and should be understood as an expression and extension of rationalization processes. Instrumentalization also has close affinities with Critical Theoretical formulations, such as Max Horkheimer's (1974) concept of "instrumental (or subjective) reason", and Jurgen Habermas's (1984) "system/lifeworld" distinction and the notion of lifeworld "colonization" by particular system objectives and "rationalities". The concept of rationalization is arguably the central concept in Weber's sociological theory, linking a broad array of social realms, practices, and ideas: religion and economics, culture and social action, forms of irrationality and rationality (Weber, 1974, 1978; Sica, 2000). Its most well-known, and succinct, expression is found in the lecture "Science as a Vocation", where Weber introduces the idea of the disenchanting tendencies of rationalization due to the elimination of "mysterious incalculable forces" and "magical means" as modes of understanding and orienting to the world (Weber, 1974). In relation to Weber's formulation, gambling is significant for a number of reasons which will be discussed; it must first be recognized that the global legitimizing and expansion of various gambling forms is itself a socio-historical process, and in some societies, particular religious beliefs and values (e.g., Protestant) have to wane in order for gambling to emerge as a legal and legitimate social, business, and consumer activity. In very broad terms, rationalization refers to the historical-cultural transformation of societies from their basis in religious worldviews to scientific/knowledge-based orientations to the world (Weber, 1946, 1992).

Weber describes a confidence, if not hubris, attached to the idea of rationalization:

The increasing intellectualization and rationalization do not...indicate an increased and general knowledge of the conditions under which one lives. It means something else, namely, the knowledge or belief that if one but wished one could learn it at any time (Weber, 1974, p. 139).
The notion of "master(ing) all things by calculation" is a central characteristic of Weber's ideal type construct of rationalization, and replaces the "mysterious incalculable forces" that have governed the human orientation to the world (Weber, 1974, p. 139).

The modern conceptualization, and "taming", of chance (Hacking, 1990), expresses important aspects of rationalization. Chance can only emerge as a cultural understanding of occurrences in the world when providential interpretations have diminished (Reith, 1996; Ottaway, 2006). Chance thus gains epistemological and ontological significance in modernity (Hacking, 1990; Reith, 1999; Ottaway, 2006). In the religious worldview, chance is latent or subsumed by God's will or a divine order, even though it is (latently) the mechanism for decisions, such as in divination practices or the distribution of resources (as in the use of lots) (Ottaway, 2006). In modernity, chance is discursively produced, but also 'tamed' by the development of probability (Hacking, 1990). Chance is not eliminated - full rationalization (i.e., complete predictive knowledge) is not possible, but chance can nevertheless be rendered knowable (e.g., the law of large numbers) for certain purposes, such as the organization of gambling games, or for various other statistical purposes.

\section{Gambling Rationalization}

Gambling rationalization - the organization of gambling games, practices, venues, etc., consequent to the application of forms of knowledge - is stimulated by legalization, which allows for state-official responses and the implementation of state-bureaucratic objectives beyond the enactments of social control when gambling is a prohibited activity. The historicaldiscursive status of gambling activity is thus altered by legalization, although not without episodes of social resistance as further legalizations and expansion are pursued. Legalization allows markets to develop, but first signifies the state's power to define the activity: in legalizing gambling the state has to take into account the national and regional cultural milieu so that legalization and market development can proceed without, or with minimal, resistance and legitimation concerns (Habermas, 1975). Since the state has a monopoly on legal decision-making, it can utilize its legal powers to allow private industry to develop gambling markets, or reserve for itself a primary role in the development of markets, either as monopolist or in some form of public-private relationship. The course of market development will depend on a variety of political-economic and cultural factors (Chambers, 2011). In broad terms, many states have seen and utilized the possibility of revenue generation that legal gambling presents, particularly through state or national lotteries. As such, the state's involvement in gambling enterprises signifies rationalizing processes, as in some countries, the state (or revenue-seeking governments), seeks to shape consumer proclivities 
through its direct role in gambling markets. Capitalist markets require stability at the political level for "(formally) peaceful chances of profit", and at the cultural level in terms of actors' subjective orientations (Weber, 1992, p. xxxii). Capitalist businesses and markets are an expression of rationalization and organized by it, in that the expectations of "foreverrenewed profit, by continuous, rational, capitalistic enterprise" depend upon the "rational capitalistic organization of labour" and the shaping of (predictable) consumer orientations (Weber 1992, pp. xxxii, xxxvi). Rationalization constitutes the organization of gambling games/venues, generates knowledge through the interactions between gamblers and the venues and technologies, shapes subjectivity and makes it amenable to market forces.

The state interest in gambling comprises an aspect of the state administration of culture, alongside the revenue interests (Yúdice, 2003). Globalizing marketstructural forces, while producing risks and uncertainties (e.g., the financial crisis of 2008) are generating new possibilities for profit seeking, while also affecting how states are able to fund and conduct themselves; the constraints generated by transnational capitalism are producing innovations pertaining to how states generate funding for their conduct. Such innovations include the selling of risk (i.e., gambling products and experiences) to citizens (Neary \& Taylor, 1998; Young, 2010). These market-structural forces entail the shaping of actor proclivities, and thus work through culture, as cultural values shift or are purposively transformed by the profit and revenue interests. The instrumentalization of gambling (for whatever purpose) depends upon the very high probability and expectation of generating profit (losses) from gamblers: the conditions to fulfil this expectation must be rendered stable and predictable - i.e., rationalized (Weber, 1992). This rationalization must occur at all levels: from laws and markets, to venues and technologies, to the subjective desires of the gambler.

The involvement in and expansion of gambling markets by private industry is an instance of the mining of experience as a new source of commodification and profit (Thrift, 2005; Schüll, 2012). This possibility of mining experience is itself dependent on cultural processes of legalization and rationalization that have produced gambling as a form of "experiential consumption". While the shape of gambling offerings differs between national and state jurisdictions, the development of gambling markets broadly exemplifies a "symbiosis" between industry and government (Livingstone \& Adams, 2011). The development of legal markets has been accounted for by terms such as "Las Vegasization", which can be treated as an ideal typical example of rationalization processes, and is discussed below. Legal markets require the shaping of gamblingconsumer proclivities, such that the experiential aspect of gambling itself becomes an object of (market) knowledge.

\section{Rationalization, Instrumentalization, and Risk}

Instrumentalization is an important dimension or offshoot of rationalization as it is the purposeful enactment of instrumental rationality (Weber, 1978). This form of rationality differs from Weber's other ideal types of rationality (e.g., value rationality) in terms of the requirement of "rational" orientation to means and ends: the consideration of a particular end also requires deliberation on the most efficient means (Weber, 1978). Weber conceived instrumental rationality to be the dominant rationality orientation in Western modernity: on the one hand it serves the (positive) development of legal-rationality, on the other it creates the "iron cage" conditions of modernity (Weber, 1992). These conditions express the negative, unintended consequences of rationalization (narratively developed in $P E$ ), and thus indicate an irony with respect to its confident claims to "master all things by calculation". The consequence, for Weber, is a "disenchanted" world (Weber, 1974, p. 139).

The contemporary sociological emphasis on "risk", and the related concept of "reflexive modernization" (Beck, 1992; Beck et al., 1994), articulates the ironies of rationalization for "second modernity" (also "risk society" (Beck, 1992) and "late modernity" (Giddens, 1991). Risk entails the application of probabilistic knowledge, whether formally (e.g., statistical knowledge) or informally (actors' subjective risk understandings) to knowing the outcome and consequence of events. "Reflexive modernization" argues that our attempts to know the world (rationalization) meet with outcomes or events (new risks) that could not be factored into our original project of knowing, but the process of knowledge production nevertheless continues to grapple reflexively with the new (unintended) outcomes.

The expansion of commercialized gambling demonstrates rationalizing processes, as will be discussed below. These processes are shaped by particular risk knowledges that are oriented to buttressing the "house edge". For the gambler, the social action of gambling means, however, that uncertainty (chance), must be preserved, or at least appear in the games since uncertainty constitutes the subjectively meaningful appeal of gambling.

The gambling enterprise (e.g., the casino) acts, in ideal typical terms, on the basis of a risk orientation, while gamblers can exhibit a variety of social action possibilities rooted in their subjective understandings of chance, probability, and uncertainty (Weber, 1978; Reith, 1999): the gambler can, as much as possible, rationalize their approach - e.g., the card counter in black jack, the mathematically-oriented grinder in poker, the handicapper in horse or sports betting, or orient in non-rational and irrational ways (such as choosing games of pure chance, gambling recklessly). The shaping of gambler proclivities however is an important dimension of instrumentalization, extending from the media realm of marketing and advertising, to 
the design of casinos and their technological offerings (games), to the psychological-behavioural and affect domains of gamblers themselves. In EGMs, chance is simulated through the technological constitution of the machines, allowing for the mining of experience and for the further instrumentalizing of affect (Baudrillard, 1983; Schüll, 2012).

Ritzer and Stillman (2001) have formulated Las Vegas casino hotels in terms of processes of disenchantment (rationalization) and enchantment. The former are revealed through the "McDonaldizing" ability to "service large numbers of customers by rationalizing operations", while the latter are presented as the ways in which the consumption spaces - the casino hotels themselves- are designed to influence affect and induce spending and consumption (Ritzer \& Stillman, 2001, p. 83; Goggin, 2011).

This disenchantment/enchantment dynamic informs "Las Vegasization": the spread of Las Vegasstyle casinos to various jurisdictions as part of economic development policy, often premised on tourism as the economic driver (Kingma, 2010). Casino gambling is, as such, configured instrumentally as economic development policy. Las Vegasization can only proceed on the basis of the cultural acceptance of Las Vegastype values: the embrace of gambling, and an emphasis on consumer-entertainment values (in contrast to, e.g., religious, ascetic, or work-ethic values (Weber, 1992)). Further, the shaping of gambling offerings itself raises lifeworld issues: for example, what does the implementation of EGMs say about citizens' gambling preferences and gambling knowledge (e.g., risks) in a particular context or jurisdiction? What does it say about the interests of the providers? How are (gambling-)citizens imagined in instrumentalized gambling policy aimed at revenue generation?

It should be noted that preceding the spatial-design enchantment emphasized by Ritzer and Stillman (2001), the primordial enchantment of gambling is found in the dynamic relationship between the institutionalized preservation of chance (uncertainty) in the activity and its temporal resolution (Goffman, 1967). The larger question here pertains to how chance is instrumentalized. This question opens out to a variety of considerations, from the organization and types of games in the gambling venues, and their effects on affect, to the relationship between lifeworld orientations to chance and risk and the larger social structural and cultural processes that shape these orientations. These processes are informed by the actions of large entities such as the state, governments, and private industry.

\section{Lifeworld and System}

Habermas's (1984) theoretical distinction between "lifeworld" and "system" offers a way of grasping the rationalization, instrumentalization, and expansion of gambling, its cultural effects (in the lifeworld) and significance for the social system. The lifeworld is formulated by Habermas to refer to the realm of intersubjective relations and communications that constitutes our everyday life and experience, and which forms the basis of shared understandings. Although the term is not used by Weber (first appearing in Edmund Husserl's work in 1936), the lifeworld equivalent in his work is the realm of culture, in which actors' social actions are enacted on the basis of subjective meaningfulness (Weber, 1978). In Weber's work, rationalization is a historical, cultural, institutional, and organizational phenomenon, but also a shaper of actors' social action(s), and constitutive of the subjective dimension of self-formation. This is demonstrated in PE (1992), in the discussion of the enactment of ascetic, methodical practices upon the emerging capitalistic actor, as well as in Weber's (1978) discussions of the socio-historical conditions for legalrational authority, which require the actor's ability to reflect on the legitimacy of abstract and universalizing principles.

In Habermas's theory, system refers to governmental, bureaucratic, and economic objectives that are subject to rationalization processes. The system dimension also includes "steering media" such as money and power (Habermas, 1987). This theory posits that communicative rationality - communication that fulfils the possibility of mutual understanding and consensus - is possible in a lifeworld context that is not distorted by asymmetries of power, and in which dialogue is free to unfold (Habermas, 1984, 1987). The legitimacy of the system objectives is anchored in the communicative basis of the lifeworld. For Habermas, the rationalization of the lifeworld is a necessary development for the possibility of communicative rationality, however such rationality is distorted by the powerful shaping abilities of the system and its objectives (Habermas, 1987).

Systemic objectives come to stand over and against the lifeworld, becoming "decoupled" from it, but have the power to colonize its communicative potentialities. For example, money is a central object of the economy - a steering medium (Habermas, 1987), which the system seeks to grow and redistribute through political and economic decisions and policies. These decisions however, may have unequal impacts, or support economic inequalities, thus influencing the lifeworld by producing asymmetries between groups or classes with money and resources, and those who lack them. The demands of systemic economic objectives thus colonize the lifeworld by making the demands appear as necessary, closing off communicative dialogue and deliberation on ends.

Habermas's theoretical emphasis on the political and communicative importance of the public sphere also relates to the system/lifeworld distinction, as the public sphere becomes subject to colonizing and instrumentalizing processes (Habermas, 1989). This will be discussed following the next section. 


\section{Gambling and Lifeworld}

The place of gambling activities in the lifeworld will vary from culture to culture, and is influenced by a variety of factors, such as religious beliefs, economic ideologies, and moral values. As mentioned, the desire to gamble is premised on socializing factors, which includes the valuing of gambling activities and the access to venues which contribute to a positive definition of gambling activities (Sutherland, 1947). In broad terms, we note in western societies the variable socio-historical career of gambling, which has seen periods of prohibition and permission, with particular trajectories dependent on national-cultural context. We also note the persistence of gambling as covert activity, particularly in urban environments, when gambling is prohibited (Sweeney, 2009; Morton, 2003). The question here concerns the form of gambling activities as lifeworld practices. As discussed, the legalization of gambling allows legal markets to develop: thus, legalization draws on the lifeworld in terms of whether the latter will permit gambling in terms of moral values, etc. This indicates the rationalization of the lifeworld for example, if anti-gambling religious beliefs wane. But legalization and the subsequent development of markets also reflexively shape the gambling lifeworld. Thus, the late $20^{\text {th }}$ century legalization and expansion of gambling has influenced the lifeworld by spreading gambling as a cultural practice (soliciting groups, such as women and the middle-class who have been historically resistant), and shaping it through processes of rationalization and instrumentalization. Gambling at the informal, communal level (Gemeinschaft) has been supplemented and reflexively shaped by the expansion of gambling at the societal level (Gesellschaft).

\section{Gambling, System, and Lifeworld Colonization}

The global expansion of gambling has been well documented (McMillen, 1996; Kingma, 2010), and continues, as casino gambling continues to grow and internet gambling becomes further legalized and expanded. Indeed, the large-scale gambling industry, led by corporations such as MGM, Wynne, Las Vegas Sands and others, exemplifies transnational capitalism (Goggin, 2020). Significantly, as gambling corporations endeavour to find entry points for expansion beyond their "home base", states have for some time incorporated within their national boundaries various gambling forms to enable state conduct for various purposes: revenue generation, economic rejuvenation, job creation, and tourism to name the most significant. As discussed, the particular national shaping of gambling depends upon the state's definition of gambling through legalization, and the development of markets in terms of the particular form of governmentmarket symbiosis (Livingstone \& Adams, 2011).

Gambling implemented for revenue generating purposes by states, and mass marketed to the public through advertising, is an example of 'system' imperatives, entailing gambling rationalization and instrumentalization (Habermas, 1984, 1987). In that gambling as a communal, cultural (and previously illegal) activity is culled, instrumentalized, and expanded for revenue purposes, it points to the colonizing of the lifeworld in a number of senses. First, through the reframing of gambling as legal activity, and hence the (re-)moralizing of the activity in terms of social values and attitudes. Second, through the rationalization and technological shaping of the activity in its various forms, and in its expansion in the cultural realm. This expansion takes place through the increase in number of venues, the promotion of gambling in the mass media, and the general increased visibility of gambling in the culture as a whole. Gambling gets transformed into a mass form of entertainment and "leisure" activity, a late modern expression of the culture industry (Adorno, 1991). While Las Vegasization exemplifies McDonaldizing processes, as Chambers (2011, p. 42) observes, particularly with respect to EGMs, these processes have been at work for some time: the "McDonaldization of gambling ... predate[s] the fastfood chain by decades". The invention of the slot machine itself is a testament to rationalization and commercialization, exploiting chance, or the appearance of it, for commercial purposes.

Where the state is the owner/promoter of gambling, this involves a reconfiguration of the state-citizen relation, as the state acts directly in the market to sell its products, and the citizen is framed as a gambling consumer. This represents a colonization, not only of the cultural realm, but also of the political realm: the state culls gambling and expands it to generate revenues, shaping culture, while legitimating and depoliticizing its involvement. It does this by obscuring the political-economic reasons for this involvement (e.g., having to raise revenues but not taxes), thus demonstrating systemic colonizing of the lifeworld through the governmental shunting of communicative action. Colonizing occurs also through the extent to which governments curtail democratic dialogue regarding the desirability of gambling expansion: in the Canadian context for example, the historical development of legal gambling has been a top-down policy action, with little public input into this development (Azmier, 2001; Smith et al., 2011). Governments intent on either implementing gambling or continuing to generate revenues from it thus have an interest in shaping the public sphere in various ways. They can limit public dialogue, downplay risks (such as addiction), and represent gambling as desirable consumer activity in its advertising. Governments can thus take on the role of market actors (stimulating gambling activity and benefiting from the revenues), obscuring the conflicted position it occupies between its role as beneficiary and role as regulator. 


\section{Putting Gambling to Work: Gambling Instrumentalization in North America}

Gambling legalization trajectories differ between national contexts, as do the particularities of rationalization processes, themselves dependent on cultural and economic factors (Chambers, 2011). However, as gambling has become globalized, broad rationalization processes are manifest, as indicated by Las Vegasization. This is in part a consequence of legalization and expansion pressures generated by jurisdictional competition for gambling revenues. Particular subnational states and provinces compete with each other to procure gambling revenues (e.g., New Jersey vs. Pennsylvania; Michigan vs. Ontario), as do intrajurisdictional sovereign groups (e.g., North American Native gambling interests vs. state or provincial government interests), as well as gambling destinations, (Macau vs. Las Vegas). Notwithstanding local national-cultural particularities shaping gambling offerings in different jurisdictions, gambling globalization rationalizes the global field through the interests of transnational gambling corporations, and the many states that utilize and instrumentalize gambling opportunities, often in partnerships with these corporations.

North American examples are provided here to illustrate instrumentalization. Legalization processes are a facet of the rationalization of culture (Weber, 1994). In the mid to late 1960s, lotteries were legalized in North America to generate state revenues. In Canada, legalization was utilized to raise funds for the 1976 Montreal Olympics. Legalization brings gambling into the state/regulatory domain, pulling it out of the shadows of illegality and making it visible as a potential object of knowledge production (Foucault, 1979; Collins, 1996). Since this initial period of legalization, there has been the simultaneous expansion of public and privately-owned gambling in the US and stateowned gambling in Canada. In the latter case, gambling has been instrumentalized by provincial governments as a form of "economic policy" in the service of revenue generation and other objectives. This instrumentalization entails a shaping of the statecitizen relationship which is discussed below. In the US, state-owned gambling has occurred in the form of lotteries, but the expansion of private casinos is used by states as a form of economic development. For example, New York, Pennsylvania, and Massachusetts have all embarked on casino expansion to generate revenues and stimulate their economies. Gambling instrumentalization also has a directly political dimension, as with the spread of Indigenous-owned gambling which, serving as it does certain politicaleconomic objectives for tribes and nations, is a political instrumentalization. Casino gambling is used to manifest and exert sovereignty, as well as generate revenues.

Gambling instrumentalization is not only productive, but dynamic. It is productive in the sense of gambling being "put to work" (Connor, 2005), i.e., implemented for various ends that are determined through decision-making or policy processes. Gambling games, and the venues, such as casinos, are rationalized to produce surpluses for the provider, and utilize enchantment strategies (Ritzer \& Stillman, 2001). In terms of the definition of the activity, the possibility of gambling serving external objectives (e.g., profits or revenues) means that the activity can be rationalized and instrumentalized to do so. Culturally, gambling instrumentalization means that the meaning of gambling activities -the lifeworld dimension -has been transformed to signify an activity no longer threatening to society. Thus, this transformation indicates the rationalization of culture, e.g., the shift away from values and meanings, whether religious, social, or economic, that proscribe against gambling.

Gambling instrumentalization is thus an integrated, dynamic feature of capitalist markets. Rendered a mass consumption activity, gambling is mobilized in advertising through the consumer society values of consumption, leisure, and entertainment. The dynamic of instrumentalization is demonstrated in the revolutionizing of new gambling products and technologies that are the product of gambling knowledges, generated by gambling-consumers in their interactions with gambling venues and games/technologies (Schüll, 2012). This aspect of gambling instrumentalization is taken up in the next section.

The building of markets requires (ongoing) legitimation as resistance occurs to forms of gambling expansion. The mass media play a role in legitimation through the broadcasting of advertisements for gambling venues and activities. In jurisdictions with state-owned gambling enterprises (such as Canada), the state plays a central role in market-building and legitimation. State-owned gambling is sold to the public as consumer activity, but the government's involvement is not (typically) topicalized in the promotions, nor are the "ends" - the uses of revenues, linked to the activity. Citizens are oriented to as revenue-generators, legitimated on the basis of gambling as an individual choice. The strategies to generate gambling revenues indicate an instrumentalizing of the public to fulfil statebureaucratic and economic objectives.

For Habermas, a democratic public sphere must cultivate dialogue and debate between citizens, outside the influence of state objectives (Habermas, 1989). The infiltration of such objectives reduces the public sphere to "a staged form of publicity" for the state (Habermas 1989, p. 201). The promotion of gambling by the state manifests an obstacle for communicative rationality in that the means (gambling) and the ends (state revenues uses, etc.) are not open to democratic dialogue. The "good" of gambling is assumed, as is the state's role in the activity. When gambling is publicized by the state as "charitable" or otherwise linked to "good causes", this is 
a shaping of the public sphere, and the (state) moraldiscursive shaping of charity and good causes. While gambling for charitable purposes appears "legitimate", it is nonetheless an expression of gambling instrumentalization. The charitable ends of gambling as designated by the state, contribute to the legitimizing and rationalizing of gambling in the broader culture. The charitable dimensions of everyday life, as expressions of solidarity and altruism (Durkheim, 1964), are colonized by the system imperatives manifested through state definitions and objectives. As the meaning of gambling is transformed through rationalization processes, public morality and the statecitizen relation are reframed.

State involvement in gambling enterprises manifests itself as system imperative first and foremost through the economic rationales for gambling and the revenue objectives to be achieved. These objectives parallel the taxation functions of the state, but are not publicly presented as taxation. The taxation function must be considered in relation to the broader economic structure, from which taxes are procured, but also in relation to public attitudes, ideologies, and discourse around taxation. As mentioned, gambling expansion has occurred in relation to neoliberalism and the particular taxation attitudes and beliefs it promotes and fosters. Thus, state gambling as system imperative is directed by the "steering medium" of money (Habermas, 1987).

As an example, in the Canadian context, in 2011 the Ontario Lottery and Gaming Corporation (OLG), which administers gambling in the province, began the "modernization" of its gambling enterprises (OLG, 2015). Among the modernization plans was an expanded lottery ticket distribution network, the introduction of online gambling, and casino expansion, including a proposed casino for the province's largest city, Toronto. This modernization, in effect a rationalization and expansion of gambling in the province to generate more revenues, has occurred in the context of a high provincial debt load and in the interests of deficit reduction. The OLG has since introduced its online offerings, and the Toronto casino plan was ultimately dropped. However, the official discussions about the casino were revealing: the talk not only forecasted the revenues that the city would receive from the OLG, but among other rationales for a casino, the revenues generated would pay for muchneed transit infrastructure in the city. ${ }^{2}$

Such predictions of revenue amounts and the uses of gambling for external objectives is a typical discursive framing of gambling as "economy policy". It exemplifies gambling rationalization and instrumentalization: the discourse appears as an "enframing" of gambling activity (Heidegger, 1977). It is remarkable that, for a phenomenon that generates

\footnotetext{
'The mayor's argument was that expansion could provide "desperately needed" jobs and be a "catalyst to attract additional investment". The OLG estimated that expansion could see the city's
}

social action on the basis of uncertainty, such discursive framing dispenses with uncertainty altogether.

\section{Chance for Sale}

An important "system" aspect related to the stateeconomy relationship, relevant to the aforementioned government-market symbiosis (Livingstone \& Adams, 2011), is the shaping of economic action. The state's involvement in gambling has been theorized as a response to economic uncertainties in neoliberal economies. Neary and Taylor (1998), in their discussion of the introduction of the British National Lottery, view the state's use of lotteries as the "law of lottery", signifying a disavowal of the welfare state's "law of insurance". Young (2010) suggests that in this economic milieu, the selling of risk through gambling products has been a successful state enterprise. Particularly in those countries where there is significant state involvement in gambling enterprises, the state is directly involved in building and maintaining markets, such as by stimulating gambling activity through advertising. Thus, as with the shaping of social attitudes to charity, the state is involved in the shaping of economic action - i.e., a governmentality of economic conduct (Weber, 1992; Foucault, 2008; Nicoll, 2019). Thus, a chance orientation is sold to citizens: buy a lottery ticket because "you could be the one!"; bet on a sports game and "get way inside the game"; "feel the excitement" of the casino!

For Horkheimer and Adorno (2002, p. 117), in a capitalist society,

Chance itself is planned; not in the sense that it will affect this or that particular individual, but in that people believe in its control. For the planners it serves as an alibi, giving the impression that the web of transactions and measures into which life has been transformed still leaves room for spontaneous, immediate relationships between human beings.

Games of chance are sold as a form of entertainment or leisure, an instrumentalized form of productive leisure, blurring the lines between work and play (Connor, 2005; Bjerg, 2011). The countenancing of the old-fashioned (Protestant) work ethic, which the state has hitherto had to support, disappears behind the chance ethic. Chance is colonized and instrumentalized to serve system interests.

Robert Herman (1967, pp. 215-216), drawing upon Roger Caillois' (1962) insights into the relationship of play and games to culture and social structure, suggests that:

The greater the physical distance between a player's home base and the gambling arena, the

revenues "climb from $\$ 15.5$-million to between $\$ 22.5$-million and \$26.5-million" (Moore, 2015). 
more aleatory games (games of chance) are encouraged, and the more mimicry is encouraged, and the more vertigo is encouraged...(the) sense of distance from home is very useful in releasing the individual from the bind of conventional responsibilities and controls. Chanciness can then increase in influence.

These comments precede the era of ubiquitous legal gambling opportunities. Now, most North Americans are a short drive from a casino, and gambling has entered the home via online gambling opportunities. The influence of "chanciness" is embedded in everyday life, and among other lifeworld effects, the gendered distinctions that served to separate the home sphere from gambling are challenged when both men and women become objects of gambling revenue extraction.

The colonization and selling of chance implicates social actors' knowledge of probabilities; social actors' subjectively meaningful orientations to chance; and social actors' orientations to social mobility and work rewards. It also raises issues with regard to the problems that follow from excessive gambling, particularly in that ubiquitous, legalized gambling is "spatially decontained" or disembedded (Giddens, 1991), making it a society (Gesellschaft) or system phenomenon rather than community (Gemeinschaft) phenomenon.

\section{Instrumentalizing Affect}

Rationalization characterizes wide-ranging processes affecting all facets of social life and culture (Weber, 1978; Habermas, 1984; Adorno, 1991; Sica, 2000). As such, the domains "outside" of the work sphere, such as leisure and "free time" have also been affected. Activities in these domains have been regarded as responses to rationalization, i.e., in some forms, as attempts to resist or escape the rationalized dimensions of everyday life (Goffman, 1967; Elias, 1986; Rojek, 1993; Sica, 2000; Horkheimer \& Adorno, 2002; Lyng, 2004). At the same time, the rationalization of various forms of leisure activities warrants scrutiny. Weber's discussions of rationalization included its effects on various cultural forms, such as art, music, and sports (Weber, 1978, 1992; Overman, 1997). Alongside the rationalization of cultural activities, it is worth considering their productive and dynamic integration into capitalist market processes, which, as with the case of gambling, also involves state processes. Thus, it is not only a question of capitalist co-optation of forms of resistance that occur in the realm of leisure, but of their dynamic commodification and instrumentalized repurposings.

Instrumentalization utilizes and extends rationalization processes: as various ends are pursued there is a dynamic process of market creation that shapes and solicits consumption. For example, the OLG "modernization" shapes the gambling markets by building gambling legitimacy (e.g., moving into previously illegal online gambling) and solicits more gambling consumption from citizens through new forms (online gambling), encouraging new groups (youth gambling) and creating greater accessibility. It is often a feature of gambling advertising to depict gambling as a form of escape (Simmel, 1971; Rojek, 1993; Binde, 2010): the OLG's lottery advertising depicts exotic vacations and the freedom from work, as well as a generalized consumption worldview. A casino trip is advertised as "your mini-vacation".

While gambling rationalization is evidenced through the widespread implementing and McDonaldizing of gambling as entertainment/leisure activity (Ritzer \& Stillman, 2001; Chambers, 2011), instrumentalization enframes gambling as productive and dynamic as behaviour becomes an object of observability, knowledge, and shaping (Collins, 1996; Schüll, 2012). Thus, the casino space is a panoptic space (Foucault, 1979), and it, and its requisite gambling technologies are constituted by knowledge aimed at the instrumentalizing of affect. This process is most apparent in the development of EGMs, as they are technologically designed to monitor players' machine interactions and render behavioural information about them, permitting the rolling out of new games and the manipulation of the casino space to generate more revenues (Schüll, 2012). This information is also implemented through strategies such as loyalty programs. The computerization of EGMs and lottery terminals allows gambling providers, which include states and governments, to collect behavioural data on "customers".

In her discussion of EGMs, Schüll (2012, p. 307) refers to the "rationalization of the aleatory domain". Instrumentalization, however, better captures the dynamic process of behavioural shaping for profit. The calculative house edge designed into the machines is made more powerful by the technologicalpsychological shaping capabilities of the machines through their ability to seduce players into experiencing the technologically-mediated "zone" (Woolley \& Livingstone, 2010; Schüll, 2012; AlbarránTorres, 2017). Thus, EGMs, "disenchanting" due to their programmed power to deplete the player's budget (Schüll, 2012), reenchant through instrumentalization. These technologically sophisticated machines render interior life into "pure circulation" (Baudrillard, 1988), producing it as a "standing reserve" (Heidegger, 1977) for behavioural shaping and profit extraction.

Outside the enclosed space of casinos, lotteries also work on affect in a more public domain through their mass-mediated soliciting of desires regarding money and consumption, appealing to emotions such as hope, to the imagination, and "waking dreams" (Durkheim, 1964; Cloftelter \& Cook, 1989; Goodman, 1996; Falk \& Menpaa, 1999; Binde, 2010). The representational appeal of mass-marketed gambling, offering escape images of "mini-vacations" and "freedom", exploits the 
disenchanting features of rationalized everyday life, at the same time that gambling instrumentalization incorporates these affects into the cultural enframing of gambling, exemplifying lifeworld colonization. The "Las Vegas" image is instrumentalized to support Las Vegasization and the appeal to affect: an entertainment imaginary, emphasizing fun and excitement, is utilized in advertising and for objectives such as tourism. Las Vegasization spreads the strategies of the "fantasy city" (Hannigan, 1998).

Instrumentalization, an expression and extension of rationalization processes, contrasts with indeterminacy and uncertainty in late modernity (Giddens, 1991). The appeals to affect and escape draw upon both, such that chance is capitalized as a response to rationalization and social structure. Thus, the (state) lottery for example, promises to enrich through chance, via a state apparatus (Althusser, 1971) that does not celebrate the merit of hard work, but rather the indeterminate framing of life chances. EGMs raise the issue of the "zone"'s relationship to the larger culture. Thus, Schüll (2012) interprets these machines in terms of their powerful ability to shape affect and transport the player away from the anxieties of economic precarity and uncertainty, precisely while capitalizing on them. Gambling instrumentalization is structured on the premise of (rationalized) gambler loss: loss is instrumentalized, but it must be obscured by various enchantment strategies.

\section{Research Implications}

In making explicit the processes of instrumentalization and rationalization as they shape legal gambling markets, this analysis opens up areas for further research. For example, in broad terms, how do the late modern characteristics of uncertainty and indeterminacy meet with rationalizing processes, producing cultural practices that are either new or that can be culled in new ways? The various ways chance is instrumentalized in everyday life, in forms of consumption but in other spheres as well, could be analyzed. How do late modern forms of "leisure" express dynamics of culture and social structure affected by factors such as financialization and globalization? Fiona Nicoll (2019, pp. 18-25) has relatedly proposed the concept of "finopower" to analyse the intersections of "gambling, finance, work and play" in neoliberal culture. To draw upon the lifeworld/system distinction, gambling expansion, particularly in its instrumentalization by the state, situates gambling as a phenomenon of the system dimension, but with lifeworld implications as gambling has been made a mainstream cultural activity. Some of these implications have been discussed, but an important one, deserving more analysis, is the rationalization of excess. The expansion of gambling has brought with it the discursive emergence of the "pathological" and "problem" gamblers and a significant research field devoted to them (Castellani,
2000; Nicoll, 2019; Akcayir et al., 2021). This emergence prompts further consideration of the framing of gambling excess as a "system" problem - occurring in the broad Gesellschaft context of legalized and expanded gambling and its instrumentalized uses. Thus, the topics discussed here address late modern cultural processes and implicate forms of subject formation. The efforts to rationalize gambling excess ("addiction", "pathology", "disorder", etc.) - i.e., to generate knowledge about it, and frame versions of "normal" and "disordered" gambling subjects are, from a genealogical perspective, manifestations of rationalization occurring at the level of the subject, and hence, lifeworld, dimension. The dynamic discursive relationship occurring between the various modes of instrumentalizing of affect, and the efforts to address or "solve" the excesses that can occur from this, speaks to the regulation of subjectivity as an expression of historical rationalization processes. The instrumentalization of gambling in terms of its affective and psychological dimensions is an extension of these processes, and could be analyzed as a particular expression of late modern "biopower" (Foucault, 1998). EGMs have been taken up for their surplus-creating capabilities (Woolley \& Livingstone, 2010; Schüll, 2012), but the rationalization of other casino games and their simulated versions, and the ongoing application of knowledge to casino design to generate consumption could be analyzed, along with the various ways gambling proclivities and tastes are shaped, and gambling subjects formed. Related to the rationalization of excess and the idea of subject formation, the meaning of loss for contemporary late modern culture appears to be occluded by the rationalized discursive notions that serve to frame, legitimate and expand commercial gambling - terms such as "responsibility", "fun", and "entertainment".

\section{Conclusion: Gambling Ain't What It Used to Be}

Gambling instrumentalization is culturally significant as a discursive framing of gambling activities in late modern culture. As such, instrumentalization is a powerful contemporary dimension of the genealogy of gambling, working alongside the various dimensions of gambling rationalization: from legalization and state policy, through the forms of knowledge created and used to shape gambling offerings, to those which generate gambling desires and proclivities in individuals and in culture more generally, and those which are used to address gambling excesses. While this discussion has focussed primarily on the macrodimensions of instrumentalization and rationalization, their implications for subject formation are seen in the production of late modern gambling consumers. As the discussion of Habermas demonstrates, late modern gambling is significant for its relationship to the "system", as well as its impacts on the "lifeworld". The social theorizing of Weber and Habermas offer powerful analytic resources for understanding and analyzing the 
place of gambling in late modern culture. The concepts addressed here, and others from their oeuvres, can well serve critical gambling studies.

\section{References}

Adorno, T. (1991). The culture industry: selected essays on mass culture. Routledge.

Akcayir, M., Nicoll, F., \& Baxter, D. G. (2021). Patterns of disciplinary involvement and academic collaboration in gambling research: A co-citation analysis. Critical Gambling Studies, 2(1), 21-28. https://doi.org/10.29173/cgs48

Albarrán-Torres, C. (2017). Kittens, farms, and wild pandas: The impact of cuteness in adult gamble-play media. In J.P. Dale, J. Goggin, J. Leyda, A. McIntyre \& D. Negra (Eds.), The aesthetics and affects of cuteness (pp. 235-252). Routledge.

Althusser, L. (1971). Ideology and ideological state apparatuses. In Lenin and philosophy and other essays (pp. 121-176). (B. Brewster, Trans.) Monthly Review Press.

Ashenden, S., \& Owen, D. (Eds). (1999). Foucault contra Habermas: Recasting the dialogue between genealogy and critical theory. SAGE.

Azmier, J. (2001). Gambling in Canada: An overview. Gambling in Canada Research Report No. 13 (August) Calgary: Canada West Foundation. CWF Publication no. 200107.

Bataille, G. (1991). The accursed share, Volume 1: Consumption, (R. Hurley, Trans.). Zone Books.

Baudrillard, J. (1983). Simulations. (P. Beitchman, P. Foss, \& P. Patton, Trans). Semiotext(e).

Baudrillard, J. (1988). America. (C. Turner, Trans.). Verso.

Beck, U. (1992). Risk society: towards a new modernity. Sage.

Beck, U., Giddens, A., \& Lash, S. (1994). Reflexive modernization: Politics, tradition and aesthetics in the modern social order. Stanford University Press.

Binde, P. (2010). 'You could become a millionaire': Truth, deception, and imagination in gambling advertising. In S. Kingma (Ed.), Global gambling: cultural perspectives on gambling organizations (pp.171-194). Routledge.

Binde, P. (2013). Why people gamble: A model with five motivational dimensions. International Gambling Studies, 13(1), 81-97. https://doi.org/10.1080/14459795.2012.712150

Bjerg, O. (2011). Poker: The parody of capitalism. University of Michigan Press.

Caillois, R. (1962). Man, play and games. Hudson.

Castellani, B. (2000). Pathological gambling: The making of a medical problem. State University of New York Press.

Chambers, K.G.E. (2011). Gambling for profit: lotteries, gaming machines, and casinos in cross-national focus. University of Toronto Press.

Clotfelter, C. T., \& Cook, P.J. (1989). Selling hope: State lotteries in America. Harvard University Press.

Collins, A. (1996). The pathological gambler and the government of gambling. History of the Human Sciences 9(3), 69-100.

Connor, Steve. (2005). Playstations, or, Playing in Earnest. Static. 1 (2005): 1.

\section{http://www.stevenconnor.com/playstations/playstations.pdf}

Cosgrave, J. F. (Ed.). (2006). The Sociology of Risk and Gambling Reader. Routledge.

Cosgrave, J.F. (2020a). Where Isn't the Action? Critical Gambling Studies, 1(1), 1-11. https://doi.org/10.29173/cgs38

Cosgrave J.F. (2020b). Gambling and Social Theory - Part 1. Critical Gambling Studies. https://doi.org/10.29173/cgs56

Cosgrave, J.F. (2021). Celebrating the Contingent: The Modern Lottery as Collective Representation in Late Capitalism. Canadian Journal of Sociology, 46 (2): 121-146.
Durkheim, E. (1964 [1895]). The division of labour in society. The Free Press.

Egerer, M., Marionneau, V., \& Virtanen, M. J. (2020). How Luhmann's systems theory can inform gambling studies. Critical Gambling Studies, 1(1), 12-22. https://doi.org/10.29173/cgs39

Elias, N. (1986). Introduction. In N. Elias \& E. Dunning, Quest for excitement: sport and leisure in the civilizing process (pp. 3-43). Basil Blackwell.

Falk, P. \& Maenpaa, P. (1999). Hitting the lottery jackpot: Lives of lottery millionaires. Oxford University Press.

Feenberg, A. (2002). Transforming technology: A critical theory revisited. Oxford University Press.

Foucault. M. (1979[1975]) Discipline and punish: The birth of the prison. (A Sheridan, Trans.). Vintage.

Foucault, M. (1998). The history of Sexuality, Vol. 1: The Will to Knowledge. (R. Hurley, Trans). Penguin.

Foucault, M. (2008). The birth of biopolitics: lectures at the College de France, 1978-1979. A.I. Davidson (Ed.). (G. Burchell Trans.). Picador.

Gephart, Jr., R. B. (2001). Safe risk in Las Vegas. M@n@gement, 4 (3),141-158. https://doi.org/10.3917/mana.043.0141

Giddens, A. (1991). Modernity and self-identity: self and society in the late modern Age. Polity.

Goffman, E. (1967). Where the action is. Interaction ritual: Essays on face to face behaviour (pp. 149-270). Anchor Books.

Goggin, J. (2011). 007 does Vegas: The diamond standard and the experience economy. In J. Frenk \& C. Krug (Eds.), The cultures of James Bond (pp. 65-81). Wissenschaflicher Verlag Trier.

Goggin, Joyce. (2020). Skyfall and global casino culture. In J. Verheul (Ed), The cultural life of James Bond: Spectres of 007 (pp. 289-309). Amsterdam University Press.

Goodman, R. (1995). The luck business. Free Press.

Habermas, J. (1975). Legitimation crisis. (T. A. McCarthy, Trans). Beacon Press.

Habermas, J. (1984 [1981]). Theory of communicative action. Volume one: Reason and the rationalization of society. (T. A. McCarthy, Trans). Beacon Press.

Habermas, J. (1987 [1981]). Theory of communicative action. Volume two: Lifeworld and system: A critique of functionalist reason. (T. A. McCarthy, Trans). Beacon Press.

Habermas, J. (1989 [1962]) The structural transformation of the public sphere: An inquiry into a category of bourgeois society. (T. Burger, Trans). Polity.

Hacking, I. (1990). The taming of chance. Cambridge University Press.

Hannigan, J. (1998). Fantasy city: pleasure and profit in the postmodern metropolis. Routledge.

Heidegger, M. (1977 [1954]). The question concerning technology and other essays. (W. Lovitt, Trans). Harper.

Herman, R. (Ed.) (1967) Gambling. Harper and Row.

Horkheimer, M. (1974). The eclipse of reason. The Seabury Press.

Horkheimer, M., \& Adorno, T.W. (2002). Dialectic of enlightenment: philosophical fragments. G. S. Noerr. (Ed.). (E. Jephcott, Trans.) Stanford University Press.

Kingma, S. (2010). Introduction: Global gambling. In S Kingma (Ed.) Global gambling: cultural perspectives on gambling organizations (pp. 1-20). Routledge.

Levy, M. (2015). Rationalization and the re-enchantment of play: The dialectics of legal gambling in Israel. Human Affairs, 25 (3), 317326. https://doi.org/10.1515/humaff-2015-0026

Livingstone, C., \& Adams, P. J. (2011). Harm promotion: Observations on the symbiosis between government and private industries in Australasia for the development of highly accessible gambling markets. Addiction, 106 (1), 3-8. https://doi.org/10.1111/j.13600443.2010.03315.x

Lyng, S. (Ed.). (2004). Edgework: The sociology of risk-taking. Routledge. 
Mauss, M. (1954 [1925]). The gift: Forms and functions of exchange in archaic societies. (I. Cunnison, Trans). The Free Press.

McMillen, J. (1996). From glamour to grind: The globalisation of casinos. In J. McMillen (Ed.), Gambling cultures: Studies in history and interpretation (pp. 263-287). Routledge.

Moore, O. (2015, June 30). Table gambling, additional slots at Woodbine one step closer to reality. Globe and Mail. June 30, 2015. http://www.theglobeandmail.com/news/toronto/tablegambling-additional-slots-at-woodbine-one-step-closer-toreality/article25214771/.

Morton, S. (2003). At odds: Gambling and Canadians 1919-1969. University of Toronto Press.

Neary, M., \& Taylor, G. (1998). From the law of insurance to the law of lottery: An exploration of the changing composition of the British state. Capital and Class 65, 55-72. https://doi.org/10.1177/030981689806500106

Nicoll, F.J. (2019). Gambling in everyday life: Spaces, moments and products of enjoyment. Routledge. https://doi.org/10.4324/9781315772646

Ontario Lottery and Gaming Corporation. (2015). Changes to OLG. http://www.modernolg.ca/why-modernize. Accessed May 21, 2015.

Ottaway, J. (2006). The national lottery and charitable gaming. Ph.D. Thesis. London School of Economics and Political Science. London, UK.

Overman, S. J. (1997). The influence of the Protestant ethic on sport and recreation. Ashgate.

Reith, G. (1999). The age of chance: Gambling in western culture. Routledge. https://doi.org/10.4324/9780203978306

Ritzer, G., \& Stillman, T. (2001). The modern Las Vegas casino-hotel: the paradigmatic new Means of Consumption', M@n@gement, 4(3), 83-99. https://doi.org/10.3917/mana.043.0083

Rojek, C. (1993). Ways of escape: modern transformations in leisure and travel Macmillan. https://doi.org/10.1057/9780230373402

Schüll, N. D. (2012). Addiction by design: Machine gambling in Las Vegas. Princeton University Press.

Sica, A. (2000). Rationalization and culture. In S. Turner (Ed.), The Cambridge companion to Weber (pp. 42-58). Cambridge University Press.

Simmel, G. (1971). The adventurer. In D.N. Levine (Ed.), On individuality and social forms (pp. 187-198). University of Chicago Press.

Smith, G. J., Schopflocher, D. P., el-Guebaly, N., Casey, D. M., Hodgins, D. C., Williams, R. M., \& Wood, R. (2011). Community attitudes toward legalised gambling in Alberta. International Gambling Studies, 11 (1), 57-79. http://dx.doi.org/10.1080/14459795.2010.550306

Sutherland, E. (1947). Principles of criminology, $4^{\text {th }}$ Ed. J.B. Lippincott.

Sweeney, M. (2009). The lottery wars: Long odds, fast money, and the battle over an American institution. Bloomsbury.

Thrift, N. (2005). Knowing capitalism. SAGE.

Weber, M. (1949 [1904]). Objectivity in social science and social policy. In The methodology of the social sciences, (E. A. Shils and H. A. Finch, Eds. and Trans.). Free Press. 50-112.

Weber, M. (1974 [1946]). Science as a vocation. In From Max Weber: essays in sociology (H. H. Gerth \& C. W. Mills, Trans. and Eds.) (pp. 129-156). Oxford University Press.

Weber, M. (1978). Economy and society: An outline of interpretive sociology, Vols. 1 \& 2 (G. Roth \& C. Wittich, Eds). University of California Press.

Weber, M. (1992 [1930]). The Protestant ethic and the spirit of capitalism (T. Parsons, Trans). Routledge.

Wilcox, S. (2021). A genealogical analysis of the medical model of problem gambling. Critical Gambling Studies, 2 (1), 97-107.
Woolley, R., \& Livingstone, C. (2010). Into the zone: Innovating in the Australian poker machine industry. In S. Kingma (Ed.), Global gambling: Cultural perspectives on gambling organizations ( $\mathrm{pp}$. 38-63). Routledge.

Young, M. (2010). Gambling, capitalism and the state: Towards a new dialectic of the risk society. Journal of Consumer Culture, 10 (2), 254-273.

Yúdice, G. (2003). The expediency of culture: uses of culture in the global era. Duke University Press.

\section{Funding and Conflict of Interest Statement}

The author has no conflicts of interest to declare. Over the last three years, the author has received research funding from the following grants:

Secondary Investigator, St. Francis Xavier University, University Council of Research Standard Research Grant. "'Enjoy your experience': Becoming a State Cannabis User." Primary Investigator: Professor Patricia Cormack. 2019. \$4,329.

Trent University SSHRC International Travel Grant, for conference presentation at The $17^{\text {th }}$ International Conference on Gambling and Risk-Taking, Caesars Palace, Las Vegas, Nevada, June 3-6, 2019. \$1,500.

\section{Author Details}

James Cosgrave's (Deptartment of Sociology, Trent University Durham, Oshawa, Ontario) research interests include the sociology of gambling, the state's involvement in the legitimation and expansion of gambling markets, and gambling regulation. His recent publications include:

"Where Isn't the Action?" Critical Gambling

Studies Spring 20201 (1): 1-11.

"Celebrating the Contingent: The Modern Lottery as

Collective Representation in Late

Capitalism." Canadian Journal of Sociology 202146 (2): 121-146, and

"Gambling Games, Money, and Late Capitalism." In The Casino, Card and Betting Games Reader: Communities, Cultures, and Play. 'Play Beyond the Computer', Volume I. ed. Mark R. Johnson. London UK; New York, NY: Bloomsbury Academic, 2022. Pp. 19-38. 